\title{
An Implementation of a Decision Support Tool to Assess Treatment of Emerging Contaminants in India
}

\author{
Zara Visanji*, Seyed M. K. Sadr, Fayyaz A. Memon \\ Centre for Water Systems, College of Engineering, Mathematics and Physical Sciences, University of Exeter, Exeter, England \\ Email: *zv208@exeter.ac.uk
}

How to cite this paper: Visanji, Z., Sadr, S.M.K. and Memon, F.A. (2018) An Implementation of a Decision Support Tool to Assess Treatment of Emerging Contaminants in India. Journal of Water Resource and Protection, 10, 422-440.

https://doi.org/10.4236/jwarp.2018.104023

Received: January 31, 2018

Accepted: April 27, 2018

Published: April 30, 2018

Copyright $\odot 2018$ by authors and Scientific Research Publishing Inc. This work is licensed under the Creative Commons Attribution International License (CC BY 4.0).

http://creativecommons.org/licenses/by/4.0/

\begin{abstract}
Emerging contaminants have been increasingly studied over the past decade to improve the understanding of their fate, occurrence and toxicological effects on the environment and human health. Originally wastewater treatment plants were not designed to remove these pollutants of emerging concern. However, research is now focusing on determining which existing treatment unit processes are suited to their removal. This research sets out to determine suitable treatment options for thirty nine emerging contaminants including various Pharmaceuticals and Personal Care products. The treatment options used in this study are taken from a developed decision support tool (WiSDOM) which formulates wastewater trains/packages for treatment of wastewater in India. The tool also evaluates the performance of each optimal solution in terms of removal of conventional pollutants (such as biochemical oxygen demand, chemical oxygen demand, total nitrogen, total phosphorous, faecal coliform etc.), using multi-objective genetic algorithms and multi-criteria decision analysis. An Excel Spreadsheet Program (ESP) was developed as an add-on to the tool, allowing the ESP to take an initial concentration of any of the thirty nine emerging contaminant and pass it through the treatment trains (generated/selected by the WiSDOM tool) to determine the removal efficiency. Three scenarios were developed to analyse the removal of emerging contaminants in India. The scenarios were designed to capture the influence of different socio-economic contexts and wastewater characteristics on the treatment technology selection. The tool generated results suggest that the use of constructed wetlands can remove a large proportion of emerging contaminants, resulting in low energy requirements and operational costs and wildlife habitats. However, the land requirement for this process is not always suited to urban areas in India. Advanced oxidation processes were also efficient at removing emerging contaminants. However, the energy requirements
\end{abstract}


for this process were high. Emerging contaminants have different physical and chemical properties; therefore, future evaluations of each chemical should be monitored separately to generate suitable technologies suited to optimal removal.

\section{Keywords}

Emerging Contaminants, Decision Support Tool, Pharmaceuticals, Personal Care Products

\section{Introduction}

Emerging contaminants (ECs) (also known as emerging pollutants, micropollutants, emerging organic contaminants and contaminants of emerging concern) [1] [2] [3], can be defined as naturally occurring, synthetic or anthropogenic chemicals/substances which are not regularly monitored, and these substances have a negative impact on the environment and on human health [4]. Other definitions also highlight the lack of monitoring of these substances and the unknown toxicity effects that they may have on the aquatic environment and towards human health. As of 2016, the NORMAN network with databases containing information on emerging substances, listed over 800 different ECs which had been identified in European aquatic waters alone [5]. One of the earliest sightings of ECs was recorded in 1965 [6], focusing its attention on steroid hormones found in the aquatic environment. Between 1965 and the 90's further publications appeared regarding pharmaceuticals and hormones as pollutants of concern in the water [7] [8]. Pharmaceuticals, personal care products (PCPs), and endocrine disrupting chemicals (EDCs) are the most common classed categories of ECs posted in the literature. However, ECs can also include steroid hormones, surfactants, perfluorinated compounds (PFCs), flame retardants, industrial additives and agents, gasoline additives, illicit drugs, UV filters (used in sunscreen products, cosmetics and creams) and nanomaterials [9] [10] [11]. Water pollution is continuously rising and a worldwide issue requires high levels of monitoring. However, ECs are not regularly monitored due to a lack of controlling requirements, legislations, and high analytical costs [4]. Historically these substances were not considered as pollutants. Therefore, treatment plants were not designed to remove them, resulting in ECs being able to freely enter freshwater and drinking water systems [12].

Sources of ECs can include pesticide application on agricultural land, parks and gardens, urban infrastructure and also domestic, hospital and industrial waste and wastewater [13] [14]. There are around 1433 different treatment works within the UK [15] and the wastewater treatment plants act as a primary source of entry for ECs to enter the aquatic environment. Hospitals are also an important source for ECs which needs to be monitored as these can release a range of substances such as disinfectants, pharmaceuticals, iodized contrast me- 
dia and heavy metals. Pharmaceutical products are excreted into urine or feces as a mixture of substances, which then travel to wastewater treatment plants [16]. Treatment plants are known to be a primary source for ECs as they are ineffective at removing these pollutants due to insufficient technology.

There are many generic water quality policies put in place which focus on priority (conventional) pollutants. However, there are no global policies regarding ECs [16]. The topic of ECs is a growing field; therefore, different projects have been launched which are currently looking into a broad range of issues surrounding ECs. For example, UNESCO-IHP initiative funded by the Swedish International and Development Cooperation Agency (Sida) is covering case studies in 20 different countries such as: Australia, Brazil, China, Ethiopia, India, Kenya, Kuwait, Mexico, Mongolia, Nigeria, Norway, Rwanda, Saint Lucia, Thailand, Tunisia, Ukraine and Vietnam [3]. Inadequate funding for equipment, detection and quantification of ECs has led to limited research on ECs in developing countries by governmental and environmental organisations [17]. Research which has been carried out in developing countries mainly focuses on the lack of removal of pollutants produced by agriculture and the textile industry [18].

India is currently one of the top pharmaceutical emerging markets in the world, and one of the largest global providers of drugs accounting for $20 \%$ of global exports. Proper waste management techniques do not exist in India, and conventional treatment plants are inefficient at the removal of ECs with sewage treatment plants discharging their effluent to rivers. Currently no official legislation revolves around ECs in India. However, there has been published papers regarding concentrations of these contaminants in India [19] [20]. Gani and Kazmi [21] provided the first review of most of the contaminants present in aquatic sources of India. Their analysis of the available data suggested that $57 \%$ of the contaminants were pesticides, $17 \%$ were pharmaceuticals, $15 \%$ were surfactants, 7\% were PCPs and 5\% were phthalates. Moving forward the aim of the review was to act as a framework for any future research or regulatory initiatives regarding monitoring of emerging contaminants in India. The Bureau of Indian Standards is not currently addressing ECs [20]; therefore, it has become essential for the creation of baseline data to act as a framework for any future research or regulatory initiatives [22].

This study aims to analyse sustainable treatment technologies for the removal of emerging contaminants in developing countries. The main objective of the study involved integrating technology information and removal rates of ECs with an existing decision support tool (WiSDOM) and a new Excel Spreadsheet Program (ESP). The ESP was developed to work alongside WiSDOM [23], taking the treatment solutions produced for wastewater in India and using these to calculate the removal of ECs and conventional pollutants in India. Due to the ubiquitous types of ECs, a database was created with over 700 ECs. However, thirty nine were chosen for this study relevant to India. Scenarios were devel- 
oped in India based on different regions throughout the country to test the application and functionality of the ESP and WiSDOM tool. The following sections summarise the information which was collected, and the methodology used to help create the ESP to calculate the most suitable treatment options.

\section{Methodology}

The overall aim of this paper is to present the application of an approach to identify optimal treatment solutions for the removal of conventional and emerging contaminants. This was achieved through the development of an Excel Spreadsheet Program (ESP) and application in conjunction with an existing tool; WiSDOM [23]. The WiSDOM tool, further explained in Section 2.2, uses optimization techniques to produce treatment solutions for the removal of conventional pollutants in India, depending on the inputted water quality and user context information. The ESP was designed to work alongside the tool, using the treatment solutions outputted to determine the capability and efficiency of the solution to remove emerging contaminants. Limited research surrounding ECs currently exists in India. Therefore, removal rates were taken from a worldwide search to help develop the ESP. This section provides a rationale for the selection of ECs to be investigated (Section 2.1), key features of the WiSDOM tool (Section 2.2) and a design description of the ESP (Section 2.3). Three main scenarios were developed to test the application of the ESP and WiSDOM tool at removing ECs from wastewater in locations that contain tourism, varied socio-economic living areas and lastly, hospital and industrial wastewater.

\subsection{Emerging Contaminants Used for the Study}

39 ECs were selected for analysis to review their removal via different treatment options. The paper published by Gani and Kazmi [19], provided a review of ECs commonly found within India. Therefore, the ECs chosen were published within Gani and Kazmi and commonly appeared in other countries and articles [11] [19] [24]-[34]. Table 1 displays the names of the ECs used for the investigation along with minimum and maximum concentrations which were recorded in the literature. These concentration values were used as for the wastewater concentrations, and therefore, were inputted into the ESP as the influent for the treatment solution.

\subsection{WiSDOM Tool}

WiSDOM stands for Wastewater Decision Support Optimiser and is a decision support tool designed for the optimal selection and formulation of wastewater treatment trains/technologies that are suited to the removal of conventional pollutants in the context of India. The tool contains a user friendly graphical interface which consists of both Genetic Algorithm Based Multi-Objective Optimisation (GA-MOO) and Multi Criteria Decision Analysis (MCDA). A detailed description of the tool and further explanation of the optimisation and decision 
Table 1. Initial concentrations and names of emerging contaminants used in the ESP.

\begin{tabular}{|c|c|c|c|}
\hline & Emerging Contaminant & $\begin{array}{c}\text { Minimum Initial } \\
\text { Concentration } \\
(\mathrm{ng} / \mathrm{l})\end{array}$ & $\begin{array}{c}\text { Maximum Initia } \\
\text { Concentration } \\
(\mathrm{ng} / \mathrm{l})\end{array}$ \\
\hline 1 & 3-benzophenone (BP3) & 638 & 10,400 \\
\hline 2 & Acetylsalicylic Acid (ASA) & 3900 & 5500 \\
\hline 3 & Amoxicillin (AMX) & 1 & 33,100 \\
\hline 4 & Ampicillin (AMP) & 23.5 & 263.5 \\
\hline 5 & Atenolol (ATN) & 1200 & 3800 \\
\hline 6 & Atrazine (ATZ) & 20 & 28,000 \\
\hline 7 & bis(2-ethylhexyl) phthalate (DEHP) & 3 & 700,000 \\
\hline 8 & Bisphenol A (BPA) & 10 & 2140 \\
\hline 9 & Caffeine (CAF) & 16000 & 209,000 \\
\hline 10 & Carbamazepine (CBZ) & 950 & 2593 \\
\hline 11 & Ciprofloxacin (CIP) & 2.2 & 236.6 \\
\hline 12 & N, N-Diethyl-meta-toluamide (DEET) & 2560 & 3190 \\
\hline 13 & Diazinon (DZN) & 1 & 684 \\
\hline 14 & Dichlorodiphenyltrichloroethane (DDT) & 1 & 6549 \\
\hline 15 & Diclofenac (DCF) & 10 & 94,200 \\
\hline 16 & Dimethyl Phthalate (DMP) & 1 & 7700 \\
\hline 17 & di-n-butyl phthalate (DnBP) & 1 & 122,000 \\
\hline 18 & Diuron (DIU) & 30 & 1960 \\
\hline 19 & Endosulfan (END) & 5000 & 15,000 \\
\hline 20 & Erythromycin (ERY) & 10 & 10,000 \\
\hline 21 & Estradiol (E2) & 2 & 50 \\
\hline 22 & Estrone (E1) & 1.2 & 170 \\
\hline 23 & Galaxolide (GAL) & 30 & 25,000 \\
\hline 24 & Gemfibrozil (GFZ) & 100 & 17,100 \\
\hline 25 & Ibuprofen (IBP) & 4 & 603,000 \\
\hline 26 & Methylparaben (MP) & 2642 & 11,601 \\
\hline 27 & Naproxen (NPX) & 2 & 529,000 \\
\hline 28 & Nonylphenol (NP) & 30 & 101,600 \\
\hline 29 & Norfloxacin (NOR) & 6.4 & 29.6 \\
\hline 30 & Ofloxacin (OFL) & 4.5 & 7.5 \\
\hline 31 & Perfluorooctanesulfonic Acid (PFOS) & 1 & 374.5 \\
\hline 32 & Perfluorooctanoic Acid (PFOA) & 1 & $1,000,000$ \\
\hline 33 & Roxithromycin (ROX) & 0.7 & 2275 \\
\hline 34 & Sucralose (SUC) & 10 & 4610 \\
\hline 35 & Sulfamethoxazole (SMZ) & 1 & 6290 \\
\hline 36 & Tetracycline (TCN) & 65 & $24,000,000$ \\
\hline 37 & Tonalide (TON) & 50 & 1930 \\
\hline 38 & Triclosan (TCS) & 3 & 23,900 \\
\hline 39 & Trimethoprim (TMP) & 60 & 6800 \\
\hline
\end{tabular}


making process can be found in [35]. This tool is used to identify optimal wastewater treatment trains based on user's defined contexts while considering a range of sustainability indicators including conventional pollutants removal, carbon emissions, resources implications and social indicators. The tool first calculates the performance of each treatment train in terms of the removal of the following conventional pollutants: 1) Chemical Oxygen Demand, 2) Biochemical Oxygen Demand, 3) Suspended Solids, 4) Total Nitrogen, 5) Phosphorous, 6) Faecal Coliform, 7) Turbidity and 8) Intestinal Nematode Eggs. Treatment trains which do not meet the water quality requirements (based on the Indian Standards on different water reuse applications) are not considered for further assessment against other sustainability indicators (e.g. energy consumption, investment, operation and maintenance costs, amount of waste generated, land requirement and social acceptability). For the purpose of this study, the GA-MOO objectives, parameters and MCDA criteria weight settings were set to their relevant default settings; as the focus was on the removal of emerging contaminants.

\subsection{Excel Spreadsheet Program}

The Excel Spreadsheet Program (ESP) was developed as a program that could effectively calculate the removal efficiencies of ECs through different treatment solutions. The treatment options (unit processes and treatment trains) used were taken from the WiSDOM tool, to allow for a clear comparison and analysis against current Indian Water Standards, and the removal efficiencies of ECs. Many of the different unit processes used within WiSDOM were adapted from Joksimovic [36].

First a database was produced regarding concentrations of the chosen ECs which included the name of the ECs, their abbreviations, CAS (Chemical Abstracts Service) number and concentrations in untreated and treated wastewater. This information was populated to provide a range of minimum and maximum concentrations of emerging concentrations (Table 1) found within recorded values within a range of sources. Next, the minimum and maximum removal rates as a percentage were populated for all 39 ECs when treated through different treatment unit processes. The removal rate of each emerging contaminant equates to the percentage of the chemical which was removed during a treatment process or stage.

The layout of the ESP consisted of two sheets in total. The first sheet has several columns. The first column contains the names of the thirty nine emerging contaminants. The next two columns included the information regarding the minimum and maximum concentration of the chosen emerging contaminants normally found in wastewaters. The top rows of the ESP, in Sheet 1, contained drop down options for each stage of treatment (preliminary, primary, secondary, tertiary and disinfection), allowing the user to change the treatment options chosen to determine the removal of ECs of each solution outputted from the 
WiSDOM tool. The drop down options for each treatment stage correlated to a treatment ID number in the second spreadsheet, allowing the relevant information to be passed through the ESP. The main body of the ESP used a functional equation that calculated the removal of each of the thirty nine ECs for each of the different treatment options selected per treatment stage. The removal of each EC was calculated using removal rates taken from published literature.

The published research looks at the overall removal rate of ECs in different treatment plants and very limited information is available on the ECs removal efficiencies for individual treatment processes. In order to address this unavailability of unit processe focused data, a number of assumprions were made to create a database of sufficient size and facilitate the running of simulation. The key assumptions are summarized in Table 2.

\subsection{Scenarios Development}

Three scenarios were developed which consisted of different inputting factors. The scenarios were processed through the WiSDOM tool, to determine the optimal treatment options for current Indian wastewater standards depending on the user constraints inputted (for example land requirement and operational and maintenance costs). The top solutions from WiSDOM were then run through the ESP to determine which had the better performance for the removal of ECs.

Table 2. Assumptions used for the ECs removal rates in the ESP.

\begin{tabular}{|c|c|}
\hline \multicolumn{2}{|r|}{ Assumptions } \\
\hline 1 & All unit processes involving an activated sludge process will have the same removal rate. \\
\hline 2 & $\begin{array}{l}\text { The treatment options set to 0\% removal rate were: Bar Screen, Grit Chamber, Coarse } \\
\text { Screen, Fine Screen, Actiflo, Enhanced Biological Phosphorous Removal (EBPR), } \\
\text { P-Precipitation and Soil Aquifer Treatment. }\end{array}$ \\
\hline 3 & $\begin{array}{l}\text { If no information is found for a unit processes regarding an ECs removal the removal rate } \\
\text { will automatically be placed at } 0 \% \text {. }\end{array}$ \\
\hline 4 & $\begin{array}{l}\text { If a value for a removal rate is found for anaerobic conditions then all other treatment } \\
\text { processes with anaerobic conditions will pose similar removal rates. }\end{array}$ \\
\hline 5 & $\begin{array}{l}\text { The overall removal rate for stabilization ponds will be split equally between the } \\
\text { different pond stages, due to a lack of information regarding the removal rate of } \\
\text { each individual pond process }\end{array}$ \\
\hline 6 & $\begin{array}{l}\text { Regarding Caffeine, all disinfection treatment options will have similar removal } \\
\text { rates unless stated otherwise in the literature. }\end{array}$ \\
\hline 7 & $\begin{array}{l}\text { If information is only found regarding the EC removal rate of one certain type of pond (i.e. } \\
\text { algal ponds), then the same removal rate will be assumed for all different pond types. }\end{array}$ \\
\hline 8 & $\begin{array}{l}\text { When only one overall value is given for more than one treatment options, such as a } \\
\text { complete treatment train, this percentage will be split between the processes } \\
\text { included in the treatment train. }\end{array}$ \\
\hline 9 & $\begin{array}{l}\text { Chlorine Dioxide and Chlorine Gas will have the same removal rates (\%) } \\
\text { unless otherwise specified in the literature. }\end{array}$ \\
\hline
\end{tabular}


The results were then analysed to find the overall best solution for both the removal of ECs and the removal of conventional water pollutants found in India.

Scenario 1 looked at investigating suitable treatment technologies which were able to remove ECs from areas affected by tourism at different scales: (A) Determining treatment options for areas that consist of "Occasional Events" such as Diwali and Ganesh Chaturthi. "Occasional Events" can include festivals, public holidays and major sporting events [25]; (B) Determining treatment options for areas in India such as "The Golden Triangle". Both scenarios have known high tourism levels resulting in an expected detection of personal care products, medicine and illicit drugs.

Scenario 2 looked at treatment technologies which were suited to removing ECs from different socio-economic groups. (A) Determining treatment options for the removal of ECs in lower class "slum" areas of India (Dahravi); (B) Determining treatment options for the removal of ECs in middle-upper class areas of India (Parel); (C) Determining treatment options for the removal of ECs in upper-class areas (Bandra). The diverse socio-economic groups will contain different treatment options for the removal of ECs, due to limitations regarding land availability and cost constraints.

Lastly, Scenario 3 looked at treatment technologies suited to the removal of ECs from different working environments. (A) Determining treatment options for the removal of ECs from Hospital wastewater (Ujjain); (B) Determining treatment options for the removal of ECs from Industrial wastewater (Perundurai).

The values assigned to different variables for each scenario are shown in Table 3.

\section{Results and Discussion}

For each scenario, the top optimal solutions generated by the MCDA section of the WiSDOM simulation were taken and analysed for their performance against a range of sustainability indicators and treatment efficiency for the conventional pollutants. The solutions were then processed through the ESP and results were displayed in a bar chart to determine the removal of ECs for each treatment train. The example solutions presented for all scenarios are intended to demonstrate the functionalities of the developed tool and response to the user inputs. Sanity of the tool provided solutions is yet to be further tested and heavily depends on the input data quality.

\subsection{Scenario 1-Areas Impacted by High Levels of Tourism}

Figure 1(a) displays the results for the treatment solution which was able to remove the most emerging contaminants from Goa, a location that contains "Occasional Events". The treatment solution used consisted of a fine screen, rotating biological contactor, constructed wetland and chlorine gas used for disinfection. This solution met the requirements of removing conventional pollutants. However, as Figure 1(a) shows, this solution did not successfully remove a 
Table 3. Data inputted into the WiSDOM too for different scenarios.

\begin{tabular}{|c|c|c|c|c|c|c|c|}
\hline \multirow{2}{*}{$\begin{array}{l}\text { Inputting Parameter for } \\
\text { WiSDOM }\end{array}$} & \multicolumn{2}{|c|}{ Scenario 1} & \multicolumn{3}{|c|}{ Scenario 2} & \multicolumn{2}{|c|}{ Scenario 3} \\
\hline & $\begin{array}{c}\text { Scenario } \\
1 \mathrm{~A}\end{array}$ & Scenario 1B & Scenario $2 \mathrm{~A}$ & $\begin{array}{l}\text { Scenario } \\
2 B\end{array}$ & Scenario $2 \mathrm{C}$ & Scenario $3 \mathrm{~A}$ & Scenario 3B \\
\hline City/Town/Village & Panaji & Jaipur & Dharavi & Parel & Bandra & Ujjain & Perundurai \\
\hline State/Region & Goa & Rajasthan & Mumbai & Mumbai & Mumabi & $\begin{array}{l}\text { Madhya } \\
\text { Pradesh }\end{array}$ & Tamil Nadu \\
\hline Population to be served & 40,017 & $3,046,163$ & $1,000,000$ & 396,122 & 337,391 & 515,215 & 24,930 \\
\hline $\begin{array}{l}\text { Wastewater produced } \\
\text { (litres/person/day) }\end{array}$ & 150 & 150 & 150 & 150 & 150 & 150 & 150 \\
\hline $\begin{array}{c}\text { Average Income } \\
\text { (INR/person/month) }\end{array}$ & 10,000 & 31,363 & 5000 & 52,454 & 180,000 & 24,600 & 24,400 \\
\hline Land Price (INR/Square metre) & 57,917 & 43,377 & 28,622 & 234,877 & 441,133 & 44,755 & 20,396 \\
\hline $\begin{array}{l}\text { Land Available for Treatment } \\
\text { Plant (Square metre) }\end{array}$ & 52,000 & 10,000 & 68,000 & 10,000 & 2000 & 40,500 & 44,500 \\
\hline $\begin{array}{l}\text { Budget available for capital costs } \\
\text { (INR) }\end{array}$ & $7 \times 10^{8}$ & $7 \times 10^{8}$ & $4 \times 10^{6}$ & $7 \times 10^{8}$ & $120 \times 10^{9}$ & $7 \times 10^{8}$ & $7 \times 10^{8}$ \\
\hline $\begin{array}{l}\text { Budget available for annual O \& } \\
\qquad M \text { costs (INR/year) }\end{array}$ & 500,000 & 500,000 & 100,000 & 500,000 & $1,000,000$ & 500,000 & 500,000 \\
\hline Intended use of effluent & $\begin{array}{c}\text { Toilet } \\
\text { Flushing }\end{array}$ & $\begin{array}{c}\text { Toilet } \\
\text { Flushing }\end{array}$ & $\begin{array}{l}\text { Non Edible } \\
\text { Crops }\end{array}$ & $\begin{array}{c}\text { Toilet } \\
\text { Flushing }\end{array}$ & $\begin{array}{c}\text { Toilet } \\
\text { Flushing }\end{array}$ & $\begin{array}{c}\text { Toilet } \\
\text { Flushing }\end{array}$ & $\begin{array}{c}\text { Toilet } \\
\text { Flushing }\end{array}$ \\
\hline Is the electricity source reliable & Yes & Yes & Yes & Yes & Yes & Yes & Yes \\
\hline
\end{tabular}

high proportion of ECs. 3-benzopheone (BP3), Acetylsalicylic Acid (ASA), Amoxicillin (AMX), Atenolol (ATN), Atrazine (ATZ), bis (2-ethylhexyl) phthalate (DEHP), Endosulfan (END), Gemfibrozil (GFZ), Perfluorooctanesulfonic Acid (PFOS) and Perfluorooctanoic Acid (PFOA) were not removed during this treatment solution. Figure 1(b) displays the treatment solution which was able to remove the most emerging contaminants from a known tourism area of Delhi. The treatment solution used contained a bar screen as preliminary treatment, followed by sedimentation without coagulant for primary treatment, then the secondary unit process used was low loaded activated sludge without denitrification and secondary sedimentation, followed by an ultrafiltration for tertiary treatment and lastly chlorine gas was used for disinfection. Compared to Scenario $1 \mathrm{~A}$, the treatment solution for Scenario $1 \mathrm{~B}$ was effective at removing a larger proportion of ECs. However, BP3, ATZ, Diazinon (DZN) and Sucralose (SUC) were still not removed.

\subsection{Scenario 2-Different Socio-Economic Groups}

Scenario 2 looked at the removal of ECs from different socio-economic groups in Mumbai. Scenario 2A focuses on analysing the removal of ECs from Dharavi, a lower class "slum" area in India. The treatment solution which was suited to 

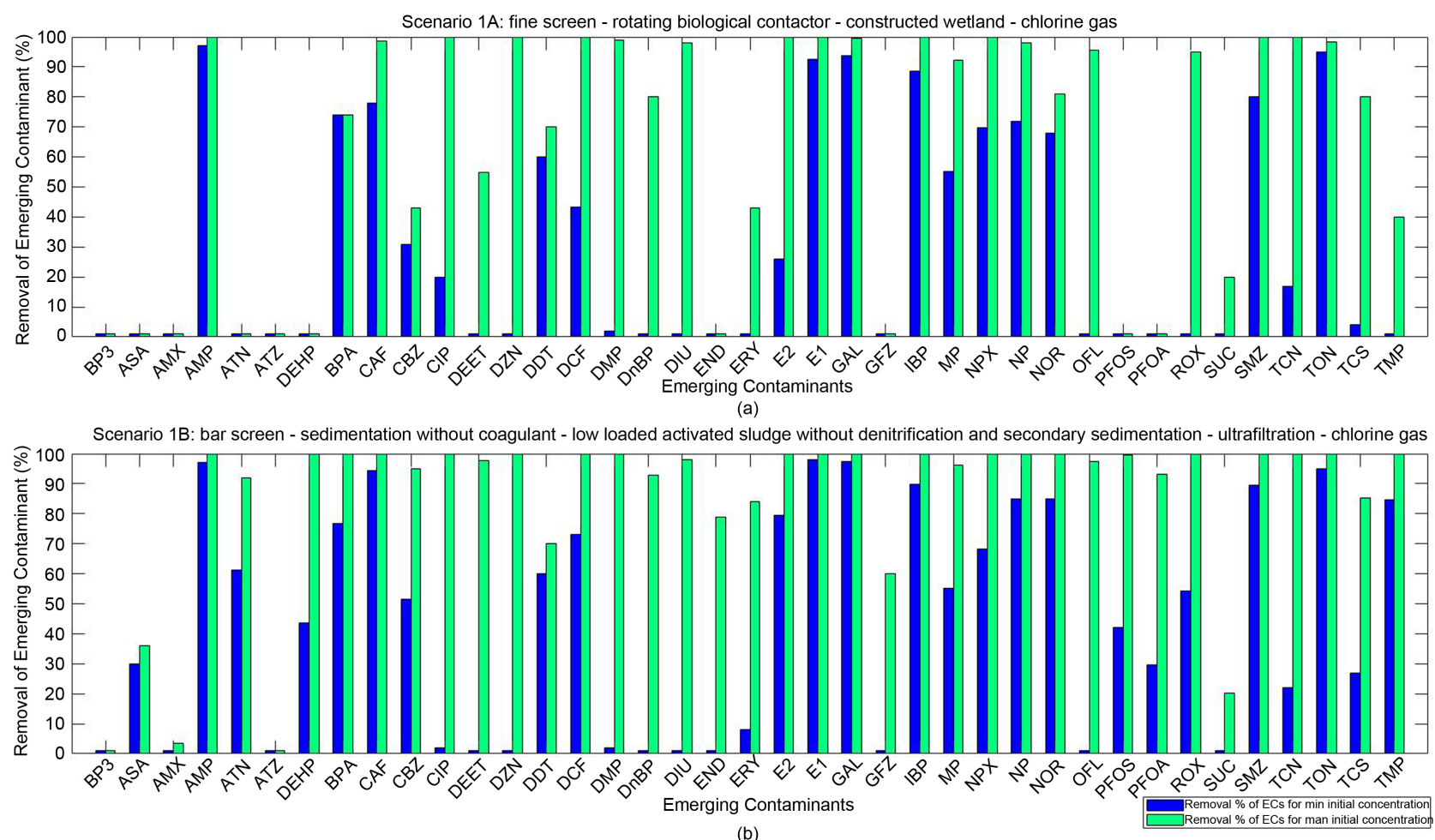

Figure 1. Removal of ECs from locations with high tourism levels: (a) Removal of ECs for Scenario 1A: “Occasional Events”. (b) Removal of ECs for Scenario 1B: “The Golden Triangle”.

meet the criteria of this location included a grit chamber, sedimentation without coagulant, constructed wetlands and chlorine gas. Section 2B looked at the removal of ECs from a middle-class area in Mumbai. The treatment solution best suited to the criteria inputted included a bar screen, sedimentation without coagulant, trickling filter followed by secondary sedimentation, nano filtration and chlorine gas. Section $2 \mathrm{C}$ focused on the removal of ECs from an upper-class area (Bandra) in Mumbai. The solution used consisted of a grit chamber, sedimentation with coagulant, stabilization pond: aerated ponds, the final stage of constructed wetlands and chlorine gas. Figure 2 presents the data for the removal of ECs from the three locations chosen in Mumbai. 3-benzopheone (BP3), Acetylsalicylic Acid (ASA) and Amoxicillin (AMX) were not removed from all three locations. Bandra was able to contain treatment technologies which were able to remove a higher proportion of ECs with all but BP3, ASA and AMX being successfully removed. Figure 2(a) presents a cheaper treatment solution in terms of cost suited to Dharavi. This solution was unable to remove Atrazine (ATZ) and Triclosan (TCS) along with the three ECs mentioned earlier. The treatment solution suited to the middle-class area was unable to remove chemicals which would be commonly found in this location such as Sucralose (SUC), Atrazine (ATZ), Diazinon (DZN) and Naproxen (NPX).

\subsection{Scenario 3-Industrial and Hospital Wastewater}

Scenario $3 \mathrm{~A}$ focused on the removal of ECs from hospital wastewater using a 


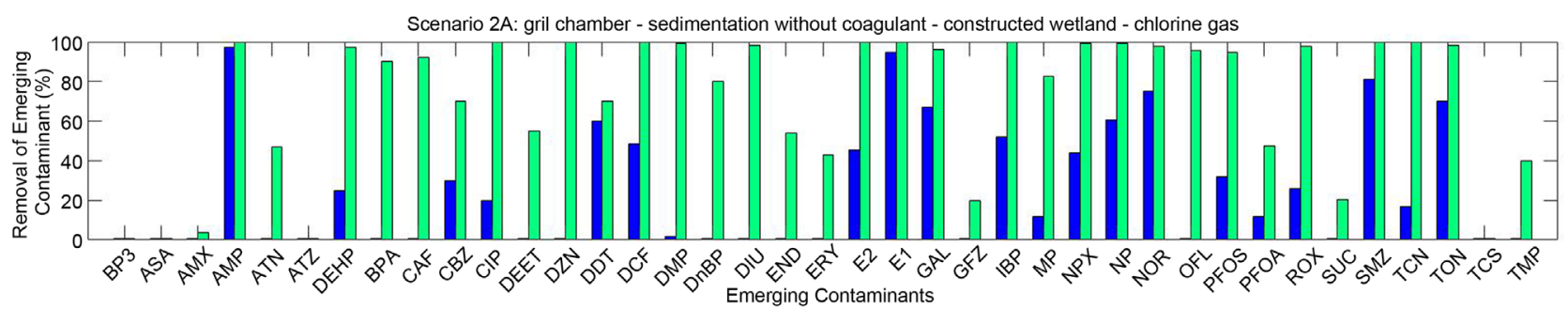

(a)
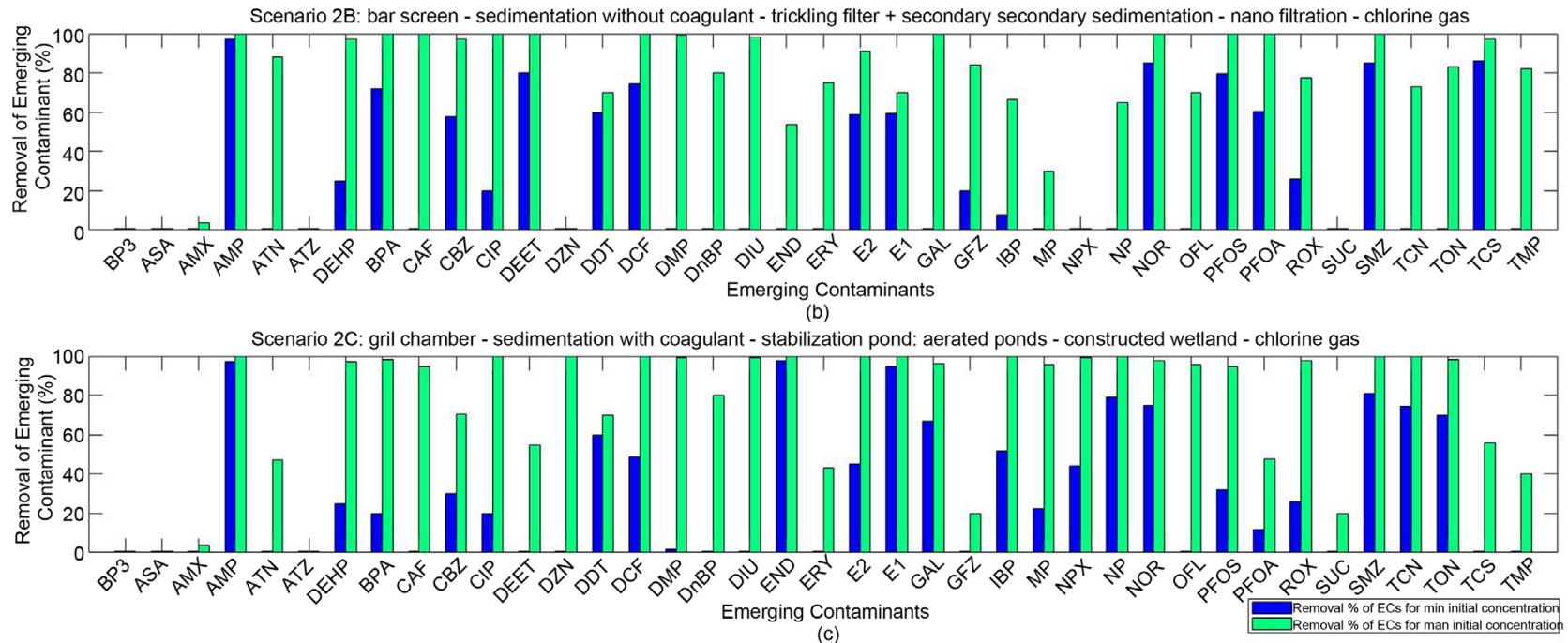

Figure 2. Removal of ECs from socio-economic groups in Mumbai: (a) Removal of ECs from Dharavi, a "slum" location (Scenario 2A), (b) Removal of ECs from Parel, a middle-class area (Scenario 2B), (c) Removal of ECs from Bandra, an upper-class location (Scenario 2C).

hospital in Ujjain as an example, whereas Scenario 3B focused on the removal of ECs from industrial wastewater in Perundurai. The treatment solution best suited to removing ECs from hospital wastewater consisted of a: coarse screen, sedimentation without coagulant, advanced oxidation $\left(\mathrm{UV} / \mathrm{H}_{2} \mathrm{O}_{2}\right)$ and chlorine gas. When determining the solution which was suited to removing ECs from hospital wastewater, it was important to focus on the removal of those pollutants commonly found in hospitals. Therefore, 3-benzopheone (BP3), Acetylsalicylic Acid (ASA), Amoxicillin (AMX), Ampicillin (AMP), Atenolol (ATN), Caffeine (CAF), Carbamazepine (CBZ), Ciprofloxacin (CIP), Diclofenac (DCF), Erythromycin (ERY), Estrone (E1), Estradiol (E2), Galaxolide (GAL), Gemfibrozil (GFZ), Ibuprofen (IBP), Naproxen (NPX), Norfloxacin (NOR), Ofloxacin (OFL), Roxithromycin (ROX), Sulfamethoxazole (SMZ), Tetracycline (TCN), Tonalide (TON) and Trimethoprim (TMP) were closely examined to determine the best result to treat the pharmaceuticals and PCPs. Figure 3(a) displays the removal of ECs and shows that ASA and NPX were the only two ECs which were unsuccessful at being removed. On the other hand, the solution for Scenario 3B focused on how the treatment options were able to remove common industrial contaminants such as BP3, bis (2-ethylhexyl) phthalate (DEHP), Bisphenol A (BPA), Dimethyl Phthalate (DMP), di-n-butyl phthalate (DnBP), Nonylphenol 


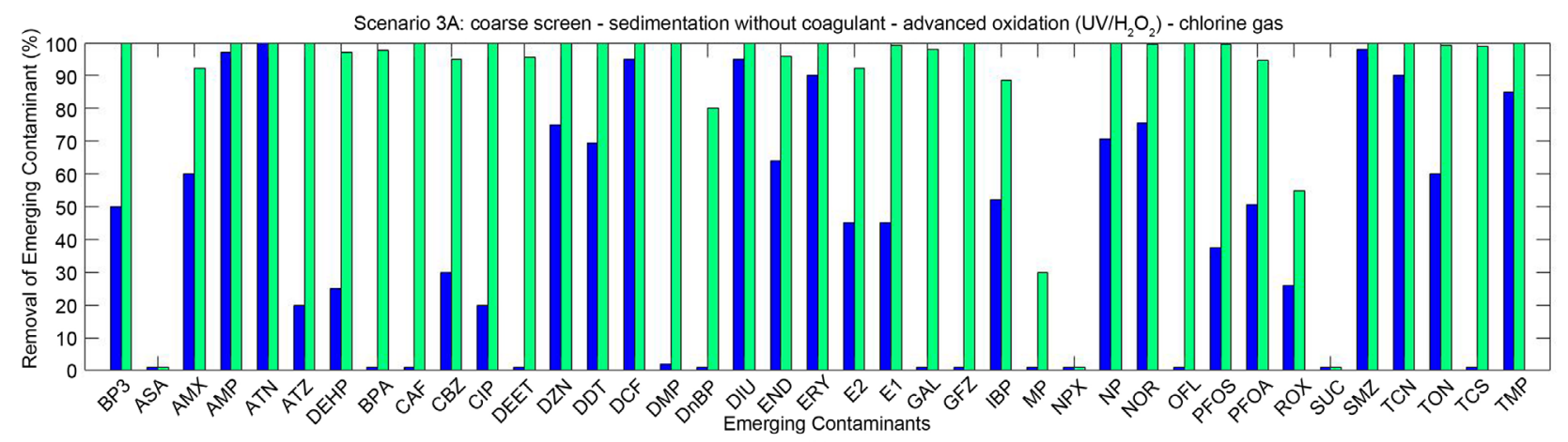

(a)

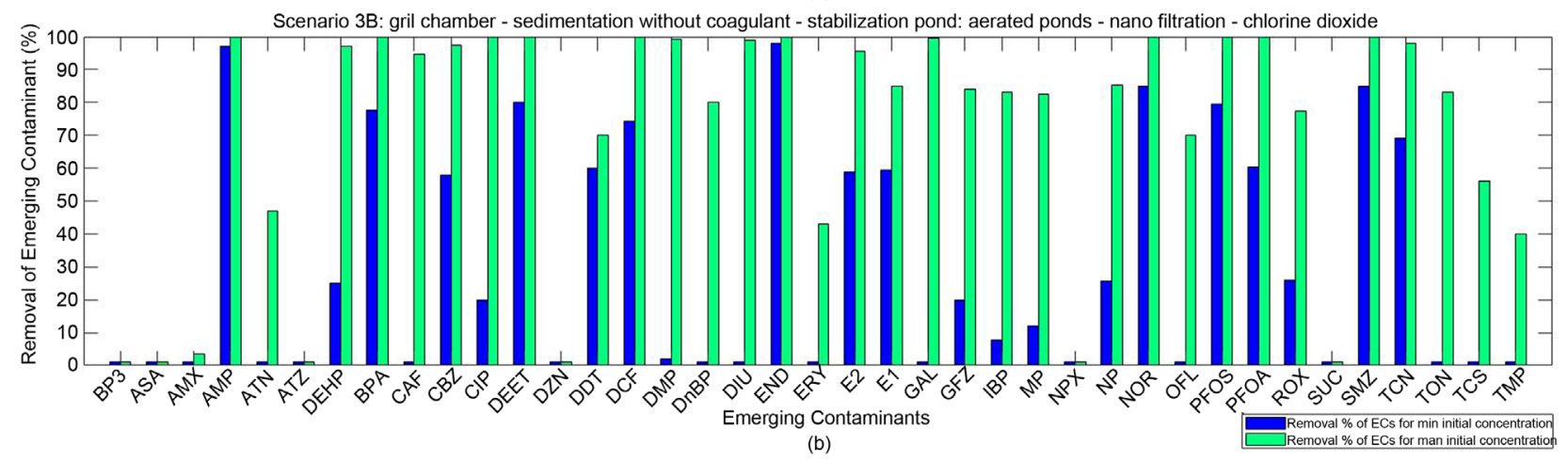

Figure 3. Removal of ECs from (a) Hospital wastewater and (b) Industrial wastewater.

(NP), Perfluorooctanesulfonic Acid (PFOS) and Perfluorooctanoic Acid (PFOA). The treatment solution used a grit chamber, sedimentation without coagulant, stabilization pond: aerated ponds, nano filtration and chlorine dioxide. Figure 3 (b) represents the removal of ECs for this solution where BP3 was the only industrial contaminant which was not removed. However, this solution also contained six other ECs (ASA, AMX, ATZ, DZN, NPX and SUC) commonly classed as PCPs and Pharmaceuticals which were not successfully removed during this solution.

\subsection{The Removal of Different Categories of Emerging Contaminants}

The following section briefly explores those ECs which were not frequently removed or did not have high removal rates. Although the different categories of ECs are listed, it is important to note that to better understand the removal of ECs we should treat each substance separately. This is because each EC has different physical and chemical properties even if they are classed in the same group as another. By separating each chemical and exploring the best removal treatment it will allow for a better understanding of how each EC is removed during treatment.

\subsubsection{Personal Care Products and Plant Protection Products}

The following categories of ECs explored in this section are biocides, plant protection products, insect repellents, musk fragrances, sweeteners and pre- 
servatives. Atrazine (ATZ), Dichlorodiphenyltrichloroethane (DDT), N, N-Diethyl-meta-toluamide (DEET), Diazinon (DZN), Diuron (DIU), Endosulfan (END) and Triclosan (TCS) are classed as biocides, plant protection products or insect repellents. These PCPs did not have high removal rates during the majority of the treatment train solutions, and ATZ, for example mainly had a removal rate of $0 \%$. This low value displayed by ATZ is seen inrecorded removal rates, of around $0 \%-25 \%$ [11]. Advanced oxidation processes (AOPs) and the use of activated carbon are able to remove ATZ at round $25 \%-100 \%$ and $0 \%$ $82.1 \%$, respectively. However, not all the treatment trains in the scenarios used these two treatment methods. Research has occurred regarding the removal of DEET and the highest removal rates could be seen during activated sludge ( $0 \%$ $90 \%)$, MBR (10\% - 90\%), Ozone (50\% - 100\%) and Nanofiltration (80\% - 100\%) [37]. Pesticides such as DDT are not widely discussed. However, disinfection activated carbon and AOPs were the best treatment options. DIU had high removal rates of greater than $80 \%$ when passed through AOPs, and found that biological treatment options such as anoxic conditions had removal rates of at least 50\% [38]. Conventional treatment methods are not suited for the removal of END. However, AOPs had a removal rate of $64 \%$ - 91\% [39]. Lastly, TCS did not fit similar removal patterns to the other chemicals within this group. TCS had high removal rates for most processes, with an $86 \%-97 \%$ removal rate for trickling filters [40].

Sucralose (SUC) is classed as an artificial sweetener and had low removal rates during the treatment trains used, reaching a $20 \%$ removal rate. The highest removal rate found for SUC was 70\% - 93\% during AOPs [41], whereas when wetlands were used the removal only reached 20\% [42]. Methylparaben (MP) is used as a preservative. The removal rates for a range of different unit processes were high with $12 \%$ - $75 \%$ removal during ponds and $88 \%$ - $94 \%$ during anaerobic biological treatment [43] and an overall removal rate of $96.8 \%$ during primary treatment, activated sludge, ultra-filtration (UF) and ozone disinfection. Both SUC and MP are less researched in comparison to other PCPs.

Overall the best treatment option to remove PCPs was using AOPs. However, some chemicals such as TCS were not greatly removed during this treatment option. AOPs are not a feasible solution in all areas especially rural areas of India due to their energy and cost requirements.

\subsubsection{Pharmaceuticals}

This section explored the removal rates of different treatment options for the two main classes of pharmaceuticals which were discussed (analgesics/anti-inflammatory and antibiotics).

Acetylsalicylic Acid (ASA), Diclofenac (DCF), Ibuprofen (IBP) and Naproxen (NPX are classed as analgesics and anti-inflammatories. ASA is a commonly researched pharmaceutical and high removal rates have been published for activated carbon and sand filtration (94\%), ultrafiltration (98\%), activated sludge (78.9\% - 83\%) and the use of an oxidation ditch (100\%) [44] [45] [46]. DCF has 
lots of information published with removal rates ranging from $10 \%-100 \%$ for a wide range of different treatment options [9] [47] [48] [49]. NPX had varying removal rates with biological treatment providing the highest removal. Anaerobic Membrane Bioreactor (MBR) had a removal rate of $75 \%$, MBR alone had $91 \%$ - 92\% removal efficiency and $91 \%$ - 95\% was seen during biological nutrient removal. The lowest removal rate (nearly $0 \%$ ) was seen during activated sludge processes [30].

Beta-lactams (Ampicillin (AMP) and Amoxicillin (AMX)), Quinolones (Ciprofloxacin (CIP), Norfloxacin (NOR) and Ofloxacin (OFL)), Macrolides (Erythromycin (ERY) and Roxithromycin (ROX)), Blood Lipid Regulators (Gemfibrozil (GFZ)), Sulfonamides (Sulfamethoxazole ((SMZ)), Trimethoprim (TMP) Tetracyclines (TCN) are different classes of antibiotics which were explored.

AMX had low removal rates, during primary treatment, of 3.6\% and the use of powdered activated carbon (PAC) had removal rates of $17.4 \%-60 \%$ [50]. The use of granular activated carbon (GAC), activated sludge and membrane filtration resulted in higher removal rates and in some cases complete removal. AMP showed lower removal rates of $67 \%-91 \%$ during activated sludge treatment. However, the use of reverse osmosis and disinfection resulted in $75 \%-100 \%$ removal. The Quinolones, CIP and OFL had close to $0 \%$ removal when activated sludge was used for treatment. These two ECs displayed similar results. However, the removal rates were lower for OFL. On the other hand, NOR was the only EC of this group to be successfully removed during filtration methods. Both the Macrolides had low removal rates during different treatment options. ROX had better removal rates during membrane filtration and microfiltration, with activated sludge processes having medium to high removal rates [50] [51] [52]. On the other hand, ERY was frequently removed during UV treatment and ozonation with removal rates varying from $4 \%$ to $100 \%$.

GFZ had high removal rates during the use of nanofiltration, AOPs, PAC and during MBR treatment. However, low removal was seen that using GAC and SMZ had generically high removal rates, with low removal efficiencies during filtration such as nanofiltration (40\% - 50\%) and ultrafiltration (20\% - 30\%) [9]. AOPs led to the complete removal of SMZ [53]. TCN exhibited low removal rates apart from when AOPs were used. Lastly, TMP had high removal rates during GAC, PAC, filtration and AOPs. However, disinfection methods were not successful at removing this EC sufficiently. Macrolides, Blood Lipid Regulators, Sulfonamides, Trimethoprim and Tetracycline all had high removal rates when AOPs were used. However, as only one EC from each category was tested it cannot be determined whether other ECs from the same group would react well to AOPs based treatments.

Although individual emerging contaminants have been grouped together and classed under different antibiotic groups, it does not mean that the ECs within the same category will have the same removal rates. Each of the different antibiotics has different removal rates which are dependent on their individual 
properties. Therefore, it is not easy to determine the best treatment option for all antibiotics.

\section{Conclusion}

ECs were previously not listed as a cause for concern. Therefore, wastewater treatment plants were not (purposely) designed to remove them. This in turn has allowed for ECs to access our water systems leading them to enter freshwater and drinking water systems. The most common types of ECs explored amongst the literature were pharmaceuticals, PCPs and EDCs. Further research is needed on the concentration of these new ECs in different water sources worldwide. The overall aim of this study was to analyse sustainable treatment options for the removal of ECs within India. The treatment solutions outputted by the WiSDOM tool focused on the removal of conventional pollutants. Therefore, they were not always effective at removing emerging contaminants. Natural processes such as wetlands and ponds are a more sustainable treatment option to remove conventional and emerging contaminants. However, the land requirement for these options is not always suited in urban areas. Equally, more energy intensive options such as AOPs are not suited in areas such as Dharavi where steady electricity sources are not viable. Each EC has its own physical and chemical components resulting in the compound to be broken down or removed in its own unique way. Therefore, to allow for the effective removal of ECs, it is important to study each compound separately including their transformations during unit processes. This study has provided the basis for further research concerning the removal of ECs. The main limitation with this research occurred due to the lack of data regarding the removal of ECs from different treatment trains. Advances are needed in regard to funding and access to equipment within India to allow for further investigations to fill the current gap within the literature. Primary data collection would allow for more accurate determination of the ECs removal rates during different treatment stages. This in turn can help developing more reliable simulations aimed at identifying optimal treatment solutions.

\section{Acknowledgements}

Authors would like to thank and acknowledge support from the following projects: EPSRC funded studentship under Water Informatics, Science and Engineering (WISE) Centre for Doctoral Training (EP/R512254/1), EC FP7-funded projects SARASWATI (308672) and NERC project on the Fate and Management of Emerging Contaminants (NE/R003548/1).

\section{References}

[1] Nam, S.W., Jo, B.I., Yoon, Y. and Zoh, K.D. (2014) Occurrence and Removal of Selected Micropollutants in a Water Treatment Plant, Chemosphere, 95, 156-165. https://doi.org/10.1016/j.chemosphere.2013.08.055

[2] Pal, A., Gin, K.Y.H., Lin, A.Y.C. and Reinhard, M. (2010) Impacts of Emerging Or- 
ganic Contaminants on Freshwater Resources: Review of Recent Occurrences, Sources, Fate And Effects. Science of the Total Environment, 408, 6062-6069. https://doi.org/10.1016/j.scitotenv.2010.09.026

[3] Zandaryaa, D.S. and Frank-Kamenetsky, D. (2015) Emerging Pollutants in Water and Wastewater: UNESCO-HELCOM Case Study on Pharmaceuticals in the Aquatic and Marine Environment in the Baltic Sea Region.

[4] Montes-Grajales, D., Fennix-Agudelo, M. and Miranda-Castro, W. (2017) Occurrence of Personal Care Products as Emerging Chemicals of Concern in Water Resources: A Review. Science of the Total Environment, 595, 601-614.

https://doi.org/10.1016/j.scitotenv.2017.03.286

[5] NORMAN (2016) Emerging Substances. http://www.norman-network.net/?q=node/19

[6] Stumm-Zollinger, E. and Fair, G.M. (1965) Biodegradation of Steroid Hormones. Journal of the Water Pollution Control Federation, 37, 1506-1510.

[7] Aherne, G.W. and Briggs, R. (1989) The Relevance of the Presence of Certain Synthetic Steroids in the Aquatic Environment. Journal of Pharmacy and Pharmacolo$g y$, 41, 735-736. https://doi.org/10.1111/j.2042-7158.1989.tb06355.x

[8] Hignite, C. and Azarnoff, D.L. (1977) Drugs and Drug Metabolites as Environmental Contaminants: Chlorophenoxyisobutyrate and Salicyclic Acid in Sewage Water Effluent. Life Sciences, 20, 337-341. https://doi.org/10.1016/0024-3205(77)90329-0

[9] Fischer, A., ter Laak, T., Bronders, J., Desmet, N., Christoffels, E., van Wezel, A. and van der Hook, J.P. (2017) Decision Support for Water Quality Management of Contaminants of Emerging Concern. Journal of Environmental Management, 193, 360-372. https://doi.org/10.1016/j.jenvman.2017.02.002

[10] Li, X., Zheng, W. and Kelly, W.R. (2013) Occurrence and Removal of Pharmaceutical and Hormone Contaminants in Rural Wastewater Treatment Lagoons. Science of the Total Environment, 445-446, 22-28. https://doi.org/10.1016/j.scitotenv.2012.12.035

[11] Luo, Y., Guo, W., Nghiem, L.D., Hai, F.I., Zhang, J., Liang, S. and Wang, X.C. (2014) A Review on the Occurrence of Micropollutants in the Aquatic Environment and Their Fate and Removal during Wastewater Treatment. Science of the Total Environment, 473-474, 619-641. https://doi.org/10.1016/j.scitotenv.2013.12.065

[12] Rodil, R., Quintana, J.B., López-Mahía, P., Muniategui-Lorenzo, S. and Prada-Rodríguez, D. (2009) Multi-Residue Analytical Method for the Determination of Emerging Pollutants in Water by Solid-Phase Extraction and Liquid Chromatography-Tandem Mass Spectrometry. Journal of Chromatography A, 1216, 2958-2969. https://doi.org/10.1016/j.chroma.2008.09.041

[13] Stuart, M., Lapworth, D., Crane, E. and Hart, A. (2012) Review of Risk from Potential Emerging Contaminants in UK Groundwater. Science of the Total Environment, 416, 1-21. https://doi.org/10.1016/j.scitotenv.2011.11.072

[14] Jurado, A., Vàzquez-Suñé, E., Carrera, J., López de Alda, M., Pujades, E. and Barceló, D. (2012) Emerging Organic Contaminants in Groundwater in Spain: A Review of Sources, Recent Occurrence and Fate in a European Context. Science of the Total Environment, 440, 82-94.

[15] Department for International Trade (2015) Water and Treated Water. https://www.gov.uk/government/publications/water-and-treated-water/water-and-t reated-water

[16] Ellis, J.B. (2006) Pharmaceutical and Personal Care Products (PPCPs) in Urban Re- 
ceiving Waters. Environmental Pollution, 144, 184-189.

https://doi.org/10.1016/j.envpol.2005.12.018

[17] Chaukura, N., Gwenzi, W., Tavengwa, N. and Manyuchi, M.M. (2016) Biosorbents for the Removal of Synthetic Organics and Emerging Pollutants: Opportunities and Challenges for Developing Countries. Environmental Development, 19, 84-89. https://doi.org/10.1016/j.envdev.2016.05.002

[18] United Nations (2011) Commodities at a Glance-Special Issue on Cotton in Africa. United Nations Conference on Trade and Development, Cotonou, July 2011, $2-30$.

[19] Gani, K.M. and Kazmi, A.A. (2017) Contamination of Emerging Contaminants in Indian Aquatic Sources: First Overview of the Situation. Journal of Hazardous, Toxic, and Radioactive Waste, 21, Article ID: 04016026.

[20] Philip, J.M., Aravind, U.K. and Aravindakumar, C.T. (2018) Emerging Contaminants in Indian Environmental Matrices-A Review. Chemosphere, 190, 307-326.

[21] Petrie, B., Barden, R. and Kasprzyk-Hordern, B. (2015) A Review on Emerging Contaminants in Wastewaters and the Environment: Current Knowledge, Understudied Areas and Recommendations for Future Monitoring. Water Research, 72, 3-27. https://doi.org/10.1016/j.watres.2014.08.053

[22] Machado, K.C., Grassi, M.T., Vidal, C., Pescara, I.C., Jardim, W.F., Fernandes, A.N., Sodre, F.F., Almeida, F.V., Santana, J.S., Canela, M.C., Nunes, C.R.O., Bichinho, K.M. and Severo, F.J.R. (2016) A Preliminary Nationwide Survey of the Presence of Emerging Contaminants in Drinking and Source Waters in Brazil. Science of the Total Environment, 572, 138-146. https://doi.org/10.1016/j.scitotenv.2016.07.210

[23] Memon, F.A., Sadr, S.M.K, Duncan, A.P., Chatterjee, P., Starkl, M., Prasad, R., Savic, D., Philip, L., Kazmi, A.A., Ghangrekar, M.M. and Singh, A. (2016) Development of a Stakeholders Informed Decision Support System for Optioneering the Treatment and Reuse of Wastewater. International Conference on Innovations in Sustainable Water and Wastewater Treatment Systems (ISWATS), Pune, 21-23 April 2016.

[24] Shanmugam, G., Sampath, S., Selvaraj, K.K., Larsson, D.G.J. and Ramaswamy, B.R., (2014) Non-Steroidal Anti-Inflammatory Drugs in Indian Rivers. Environmental Science and Pollution Research, 21, 921-931. https://doi.org/10.1007/s11356-013-1957-6

[25] Subedi, B., Balakrishna, K., Joshua, D.I. and Kannan, K. (2017) Mass Loading and Removal of Pharmaceuticals and Personal Care Products including Psychoactives, Antihypertensives, and Antibiotics in Two Sewage Treatment Plants in Southern India. Chemosphere, 167, 429-437. https://doi.org/10.1016/j.chemosphere.2016.10.026

[26] Lapworth, D.J., Baran, N., Stuart, M.E. and Ward, R.S. (2012) Emerging Organic Contaminants in Groundwater: A Review of Sources, Fate and Occurrence. Environmental Pollution, 163, 287-303.

[27] Gavrilescu, M., Demnerová, K., Aamand, J., Agathos, S. and Fava, F. (2015) Emerging Pollutants in the Environment: Present and Future Challenges in Biomonitoring, Ecological Risks and Bioremediation. New Biotechnology, 32, 147-156. https://doi.org/10.1016/j.nbt.2014.01.001

[28] la Farré, M., Pérez, S., Kantiani, L. and Barceló, D. (2008) Fate and Toxicity of Emerging Pollutants, Their Metabolites and Transformation Products in the Aquatic Environment. TrAC Trends in Analytical Chemistry, 27, 991-1007. https://doi.org/10.1016/j.trac.2008.09.010 
[29] Kim, S. and Choi, K. (2014) Occurrences, Toxicities, and Ecological Risks of Benzophenone-3, a Common Component of Organic Sunscreen Products: A Mini-Review. Environment International, 70, 143-157. https://doi.org/10.1016/j.envint.2014.05.015

[30] Nakada, N., Tanishima, T., Shinohara, H., Kiri, K. and Takada, H. (2006) Pharmaceutical Chemicals and Endocrine Disrupters in Municipal Wastewater in Tokyo and Their Removal during Activated Sludge Treatment. Water Research, 40, 3297-3303. https://doi.org/10.1016/j.watres.2006.06.039

[31] Dargnat, C., Teil, M.J., Chevreuil, M. and Blanchard, M. (2009) Phthalate Removal throughout Wastewater Treatment Plant. Science of the Total Environment, 407, 1235-1244. https://doi.org/10.1016/j.scitotenv.2008.10.027

[32] Ahmed, M.B., Zhou, J.L., Ngo, H.H., Guo, W., Thomaidis, N. S. and Xu, J. (2017) Progress in the Biological and Chemical Treatment Technologies for Emerging Contaminant Removal from Wastewater: A Critical Review. Journal of Hazardous Materials, 323, 274-298. https://doi.org/10.1016/j.jhazmat.2016.04.045

[33] Chen, J., Wei, X.D., Ying, Y.S., Liu, S.S., He, L.Y., Su, H.C., Hu, L.X., Chen, F.R. and Yang, Y.Q. (2016) Removal of Antibiotics and Antibiotic Resistance Genes from Domestic Sewage by Constructed Wetlands: Optimization of Wetland Substrates and Hydraulic Loading. Science of the Total Environment, 565, 240-248. https://doi.org/10.1016/j.scitotenv.2016.04.176

[34] Subedi, B. and Kannan, K. (2014) Fate of Artificial Sweeteners in Wastewater Treatment Plants in New York State, U.S.A. Environmental Science \& Technology, 48, 13668-13674. https://doi.org/10.1021/es504769c

[35] Sadr, S.M.K., Memon, F.A. and Johns, M. (2017) Deliverable 6.5: Supporting Consolidation, Replication and Up-Scaling of Sustainable Wastewater Treatment and Reuse Technologies for India. University of Exeter, Exeter.

[36] Joksimovic, D. (2007) Decision Support System for Planning of Integrated Water Reuse Projects. Ph.D. Thesis, University of Exeter, Exeter.

[37] Merel, S. and Snyder, S.A. (2016) Critical Assessment of the Ubiquitous Occurrence and Fate of the Insect Repellent $N, N$-Diethyl-m-Toluamide in Water. Environment International, 96, 98-117. https://doi.org/10.1016/j.envint.2016.09.004

[38] Rodriguez-Narvaez, O.M., Peralta-Hernandez, J.M., Goonetilleke, A. and Bandala, E.R. (2017) Treatment Technologies for Emerging Contaminants in Water: A Review. Chemical Engineering Journal, 323, 361-380.

https://doi.org/10.1016/j.cej.2017.04.106

[39] Shah, N.S., He, X., Khan, H.M., Khan, J.A., O’Shea, K.E., Boccelli, D.L. and Dionysiou, D.D. (2013) Efficient Removal of Endosulfan from Aqueous Solution by UV-C/Peroxides: A Comparative Study. Journal of Hazardous Materials, 263, 584-592.

[40] Thompson, A., Griffin, P., Stuetz, R. and Cartmell, E. (2005) The Fate and Removal of Triclosan during Wastewater Treatment. Water Environment Research, 77, 63-67. https://doi.org/10.2175/106143005X41636

[41] Xu, Y., Lin, Z. and Zhang, H. (2016) Mineralization of Sucralose by UV-based Advanced Oxidation Processes: UV/PDS versus $\mathrm{UV} / \mathrm{H}_{2} \mathrm{O}_{2}$. Chemical Engineering Journal, 285, 392-401. https://doi.org/10.1016/j.cej.2015.09.091

[42] Sharif, F. (2012) Use of Ozonation and Constructed Wetlands to Remove Contaminants of Emerging Concern from Wastewater Effluent. Arizona State University, Tempe.

[43] Londoño, Y.A. and Peñuela, G.A. (2015) Anaerobic Biological Treatment of Me- 
thylparaben in an Expanded Granular Sludge Bed (EGSB). Water Science \& Technology, 71, 1604-1610. https://doi.org/10.2166/wst.2015.118

[44] Ayyash, F., Khamis, M., Khalaf, S., Thawabteh, A. and Karaman, R. (2015) Removal of Aspiring, Salicylic Acid, Paracetamol and P-Aminophenol by Advanced Membrane Technology Activated Charcoal and Clay Micelles Complex. International Case Studies Journal, 4, 74-111.

[45] Cardenas, M.A.R., Ali, I., Lai, F.Y., Dawes, L., Their, R. and Rajapakse, J. (2016) Removal of Micropollutants through a Biological Wastewater Treatment Plant in a Subtropical Climate, Queensland-Australia. Journal of Environmental Health Science and Engineering, 14, 14.

[46] Nugroho, W.A., Reungoat, J. and Keller, J. (2010) The Performance of Biological Activated Carbon in Removing Pharmaceuticals in Drinking Water Treatment. Journal of Applied Sciences in Environmental Sanitation, 5, 131-141.

[47] Sui, Q., Cao, X., Lu, S., Zhao, W., Qiu, Z. and Yu, G. (2015) Occurrence, Sources and Fate of Pharmaceuticals and Personal Care Products in the Groundwater: A Review. Emerging Contaminants, 1, 14-24.

https://doi.org/10.1016/j.emcon.2015.07.001

[48] Anumol, T., Vijayanandan, A., Park, M., Philip, L. and Snyder, S.A. (2016) Occurrence and Fate of Emerging Trace Organic Chemicals in Wastewater Plants in Chennai, India. Environment International, 92-93, 33-42. https://doi.org/10.1016/j.envint.2016.03.022

[49] Rigobello, E.S., Dantas, A.D.B., Bernardo, L.D. and Vieira, E.M. (2013) Removal of Diclofenac by Conventional Drinking Water Treatment Processes and Granular Activated Carbon Filtration. Chemosphere, 92, 184-191. https://doi.org/10.1016/j.chemosphere.2013.03.010

[50] Michael, I., Rizzo, L., McArdell, C.S., Manaia, C.M., Merlin, C., Schwartz, T., Dagot, C. and Fatta-Kassinos, D. (2013) Urban Wastewater Treatment Plants as Hotspots for the Release of Antibiotics in the Environment: A Review. Water Research, 47, 957-995. https://doi.org/10.1016/j.watres.2012.11.027

[51] Park, J., Yamashita, N., Park, C., Shimono, T., Takeuchi, D.M. and Tanaka, H. (2017) Removal Characteristics of Pharmaceuticals and Personal Care Products: Comparison between Membrane Bioreactor and Various Biological Treatment Processes. Chemosphere, 179, 347-358. https://doi.org/10.1016/j.chemosphere.2017.03.135

[52] Vymazal, J., Dvořáková Březinová, T., Koželuh, M. and Kule, L. (2017) Occurrence and Removal of Pharmaceuticals in Four Full-Scale Constructed Wetlands in the Czech Republic-The First Year of Monitoring. Ecological Engineering, 98, 354-364. https://doi.org/10.1016/j.ecoleng.2016.08.010

[53] Jiang, J.Q., Zhou, Z. and Sharma, V.K. (2013) Occurrence, Transportation, Monitoring and Treatment of Emerging Micro-Pollutants in Waste Water-A Review from Global Views. Microchemical Journal, 110, 292-300. 